\title{
Short communication: expanding the range of services to the survivors of Ebola virus disease in the Democratic Republic of the Congo
}

\author{
Saurabh RamBihariLal Shrivastava ${ }^{1}$, Prateek Saurabh Shrivastava ${ }^{2}$
}

1. Member of the Medical Education Unit \& Institute Research Council, 2. Department of Community Medicine, Shri Sathya Sai Medical College \& Research Institute, Sri Balaji Vidyapeeth, Deemed to be University, Ammapettai Village, Sembakkam Post, Chengalpet District, India

\begin{abstract}
Objectives: The objectives of the article are to assess the role of a strategic response in the prevention and control of the disease and the need for extending supports to the survivors of disease.

Introduction: Since the start of the August last year, a new outbreak of Ebola virus disease has been reported in provinces of the Democratic Republic of the Congo.

Methods: As of now, close to 1170 cases and 740 deaths have been attributed to the diseases due to the associated complications in the region.

Results: In order to effectively respond to the outbreak, a wide range of strategies have been proposed. It is a fact that the survivors of the disease outbreak face multiple challenges, the task of organizing eye clinics to promote early detection of the problems among the survivors has been initiated.

Conclusion: In conclusion, Ebola virus disease is a life threatening disease and is linked with a wide range of complications, including those involving eyes. Thus, the need of the hour is to formulate a strategic response comprising of different strategies which not only aim to reduce the incidence of the disease, but also to extend quality assured care to the survivors.
\end{abstract}

Keywords: Ebola virus disease; Democratic Republic of Congo; eye; survivors.

DOI: https://doi.org/10.4314/ahs.v20i2.14

Cite as: Shrivastava SR, Shrivastava PS. Short communication: expanding the range of services to the survivors of Ebola virus disease in the Democratic Republic of the Congo. Afri Health Sci. 2020; 20(2): 656-657. https://doi.org/10.4314/abs.v20i2.14

\section{Introduction}

Since the start of the August last year, a new outbreak of Ebola virus disease has been reported in provinces of the Democratic Republic of the Congo. ${ }^{1}$ Efforts have been taken to strengthen the surveillance activities and identify the precise number of cases and the associated

\section{Corresponding author:}

Saurabh RamBihariLal Shrivastava, 3rd floor, Department of Community

Medicine, Shri Sathya Sai Medical College

\& Research Institute, Ammapettai village,

Thiruporur-Guduvancherry Main Road,

Sembakkam Post, Chengalpet District- 603108,

Tamil Nadu, India

Telephone number: +919884227224

Email: drshrishri2008@gmail.com deaths. ${ }^{2,3}$ Till September 29th 2019, more than 3070 confirmed cases and 2015 deaths have been attributed to the diseases due to the associated complications (such as organ failure, bleeding, jaundice, delirium, shock, seizures, coma, etc.) in the South Kivu, North Kivu and Ituri provinces of the nation. ${ }^{4}$ The present outbreak reminds about the West African outbreak (2014-2016) of the disease in the region and the long-term aftereffects it has left in the system and the community.,

\section{Mounting an effective response}

In order to effectively respond to the outbreak, a wide range of strategies have been proposed, including strengthening multi-sectoral response at all levels, information management system, diagnostic modalities, infection prevention \& control measures \& surveillance activities to ensure the identification of active case \& contact tracing. ${ }^{3}$ Moreover, steps have been taken to pro-

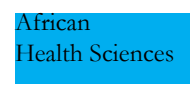

C 2020 Shrivastava SR et al. Licensee African Health Sciences. This is an Open Access article distributed under the terms of the Creative commons Attribution
License (https://creativecommons.org/licenses/BY/4.0), which permits unrestricted use, distribution, and reproduction in any medium, provided the original
work is properly cited. 
mote appropriate management of cases, measures for the survivors, vaccination of high-risk groups, ensuring safe and dignified burials, delivery of psychosocial care and motivating people to avail heath services. ${ }^{3,5}$ Further, efforts have been taken to improvise risk communication, strengthen human resources \& international health regulations and warrant financial support to carry out all the planned activities. ${ }^{3,5}$

\section{Eye complications and the response}

It is a fact that the survivors of the disease outbreak face multiple challenges, including diminished vision originating because of the inflammation of the eyes. ${ }^{1}$ The available estimates suggest that close to one-fifth of the disease survivors experience some form of eye problem, and there is a significant need to diagnose and manage the same at the earliest to prevent serious complications. ${ }^{1,6}$ Acknowledging the magnitude of the problem and the need to intervene at the earliest, the World Health Organization in collaboration with the national Health Ministry has initiated the task of organizing eye clinics to promote early detection of the problems among the survivors. ${ }^{1}$

In continuation, training sessions for the local eye specialists has been organized, wherein they are being trained to diagnose and provide specialized care for the disease survivors. ${ }^{1}$ To date, in excess of 250 survivors have been examined and complications like uveitis has been reported among the survivors, but the good news is that the incidence of such complications is significantly less than what was reported in the 2014 outbreak. The feedback obtained from the involved agencies has been positive and the plan is to continue the follow-up among survivors on a monthly basis and the vision is to also ensure delivery of medical, biological and psychological care. ${ }^{1,3,6}$

\section{Conclusion}

Ebola virus disease is a life threatening disease and is linked with a wide range of complications, including those involving eyes. Thus, the need of the hour is to formulate a strategic response comprising of different strategies which not only aim to reduce the incidence of the disease, but also to extend quality assured care to the survivors.

\section{Source of support}

None.

\section{Conflicts of interests}

None to be declared.

\section{References}

1. World Health Organization. Eye care for Ebola survivors; 2019. Available from: https://www.who.int/newsroom/feature-stories/detail/eye-care-for-ebola-survivors

2. Shrivastava SR, Shrivastava PS, Ramasamy J. An indispensable need to offer comprehensive clinical care to the Ebola survivors. Ann Trop Med Public Health. 2016; 9(6): 425-426.

3. World Health Organization. Strategic response plan for the Ebola virus disease outbreak in the provinces of north Kivu and Ituri. Geneva: WHO press; 2019. p: 1-24. 4. World Health Organization. Situation reports; 2019. Available from: https://www.afro.who.int/health-topics/ ebola-virus-disease

5. Shrivastava SR, Shrivastava PS, Ramasamy J. Public health strategies to ensure optimal community participation in the Ebola outbreak in West-Africa. J Res Med Sci. 2015; 20(3): 318-319.

6. Shantha JG, Hayek BR, Crozier I, Gargu C, Dolo R, Brown J, et al. Development of a screening eye clinic for Ebola virus disease survivors: Lessons learned and rapid implementation at ELWA Hospital in Monrovia, Liberia 2015. PLoS Negl Trop Dis. 2019; 13(3): e0007209. 